\title{
Review of different pushover analysis methods applied to masonry buildings and comparison with nonlinear dynamic analysis
}

\author{
Yohei Endo ${ }^{1}$, Luca Pelà2*, Pere Roca² \\ 1 Shinshu University, Department of Architecture, 4-17-1 Wakasato, 380-8553, Nagano, Japan \\ 2 Technical University of Catalonia (UPC-BarcelonaTech), Department of Civil and Environmental \\ Engineering, Jordi Girona 1-3, 08034 Barcelona, Spain \\ *corresponding author, e-mail: luca.pela@upc.edu ,phone: +34 934011036
}

\begin{abstract}
This paper presents the comparison among different nonlinear seismic analysis methods applied to masonry buildings, i.e. pushover analyses with invariant lateral force distributions, adaptive pushover analysis and nonlinear dynamic analysis. The study focuses on the influence of lateral force distribution on the results of the pushover analysis. Two simple benchmark case studies are considered for the purpose of the research, i.e. a four-wall masonry building prototype without floor rigid diaphragms and a two-wall system with a cross-vault. The comparative study offers a useful review of pushover analysis methods for masonry structures and shows advantages and possible limitations of each approach.

KEY WORDS: Masonry, Historical Structure, Earthquake, Nonlinear Static Analysis, Nonlinear Dynamic Analysis, Adaptive Pushover Analysis, Lateral Force Distribution, FEM.
\end{abstract}

\section{INTRODUCTION}

Nonlinear static (pushover) analysis, usually based on macro-modelling, is one of the frequently used tools for seismic assessment of masonry structures [Pelà et al. 2009, Lagomarsino et al. 2014]. Although pushover analyses with invariant lateral force distribution have been used frequently for seismic assessment, it is known that they have some limitations. For instance, they cannot detect changes caused in nonlinear dynamic characteristics due to the evolution of damage in the structure [Krawinkler 1995].

Considering the limitations of Invariant-force Pushover Analysis (IPA), advanced pushover analyses like Multi-mode or Modal Pushover Analysis (MPA) and Adaptive Pushover Analysis (APA) were formulated [Federal Emergency Management Agency 2004, Aydinoglu 2003, Papanikolaou and Elnashai 2005]. MPA has been developed by various researchers such as 
Sasaki et al. [1998], Reinhorn [1997], Chopra and Goel [2002], and Jan et al. [2004]. MPA permits the consideration of higher modes in pushover analysis. This method has been applied mainly to lumped mass systems like frame structures. When MPA is applied to elastic models, it should be equivalent to response spectrum analysis [Chopra and Goel 2002]. One of the limitations of this method is that the sequence of damage development cannot be directly controlled, since the final deformed shape can be represented only by superposition of the deformed shapes from each mode [Chopra and Goel 2004]. Also, the use of modal combination rules (e.g. SRSS or CQC) to determine the total response starting from the peaks of the "modal" pushover responses seems still a rough approximation when dealing with a nonlinear response. Almost in parallel with MPA, APA was developed by different researchers such as Bracci et al. [1997], Albanesi et al. [2002] and Antoniou and Pinho [2004]. This method can represent the development of the damage during the analysis by updating the lateral force distribution pattern as damage propagates. APA considers the state of resistance and of inelasticity at the current step and updates the lateral load distribution accordingly [Papanikolaou and Elnashai 2005].

For pushover analysis, the lateral distribution pattern of the equivalent seismic load has a certain influence on the results. Frequently-used distribution patterns are those proportional to the mass of the structure [Betti and Vignoli 2011, Roca et al. 2013, Ivancic et al. 2014] and to the first modal shape [Lourenço et al. 2012]. The former load distribution has been shown to induce more extensive damage while the latter usually predicts more damage on higher parts of the structure [Galasco et al. 2006]. Saloustros et al. [2015] applied both lateral force distributions to assess the seismic response of the nave of an historical church and found remarkable differences in the results, with the mode proportional pattern providing lower estimated capacity than the mass proportional one. Simões et al. [2014] also compared mass and pseudo-triangular force distributions in the pushover analysis of a five-storey unreinforced masonry building with flexible timber floors. The mass-proportional pushover analysis showed higher load capacity and stiffness, while the pseudo-triangular one showed higher displacement capacity. Lagomarsino et al. [2014] compared both force distributions in the pushover analysis of a historical aggregate using an equivalent frame model. They mentioned the limitations of such distributions in representing the effects of higher order modes in complex aggregates.

Lourenço et al. [2011] carried out seismic analyses of a six-story unreinforced masonry building without box behaviour (i.e. with flexible floor and roof). They compared pushover analyses with lateral force distribution proportional to the masses of the structure and to the first mode shape, APA and nonlinear dynamic analysis. The pushover analyses proportional to the first mode provided an estimation of the load capacity in agreement with Nonlinear Dynamic Analysis (NDA). However, the authors suggested to apply with caution the pushover analyses to masonry buildings without box behaviour and highlighted the importance of carrying out more 
research. Out-of-plane behaviour should be analysed individually by means of limit analysis with macro elements. Endo et al [2015] carried out seismic assessment of a historical masonry church struck by L'Aquila earthquake. They adopted pushover analysis with lateral force distribution proportional to the masses of the structure, limit analysis and NDA. Pushover analysis on the entire structure was revealed to be a practical approach for seismic assessment of a historical church although limitations were observed in the prediction of capacity and mechanisms. However, the authors suggested the combination of distinct analysis methods in order to cover the limitations of each one.

Eurocode 8 [CEN 2004] suggests the application of the N2 method proposed by Fajfar [2000], based on the combination of pushover analysis with the capacity spectrum approach. This method correlates the displacement capacity of the structure to the displacement demand of the expected earthquake. For symmetrical structures, good performance was observed. Extensions of the N2 method were proposed for the application to asymmetrical frame buildings [Fajfar et al. 2005], buildings irregular in plan [Magliulo et al. 2012] and structures irregular both in plan and height [Kreslin and Fajfar 2010].

Alternative seismic analysis methods to pushover analysis are response spectrum analysis [Pelà et al. 2013a] and NDA [Pelà et al. 2013b, Milani et al. 2014]. For accurate evaluation of structural seismic response, NDA requires an input accelerogram consistent with the seismic hazard at the site [Penna et al. 2014]. Nevertheless, its practical application still poses difficulties because of intrinsic complexities and high computer effort demand [Mwafy and Elnashai 2001]. According to Casolo and Uva [2013], NDA is suggested to be used when detailed vulnerable assessment is necessary. Penna et al. [2013] observed that NDA requires the definition of structural performance levels based on damage and/or displacement indicators.

In this paper, different nonlinear seismic analysis methods such as pushover analysis and NDA are applied. A review of the currently available pushover approaches is carried out through their application to two simple benchmark case-studies. The first case is a one-storey four-wall masonry building, without rigid floor diaphragm, whereas the second one is a one-storey twowall building with a weighty cross vault. Such structural typologies are simpler modules that can be often found in historical masonry construction. So as to limit the complexity of the analyses, geometrically simple masonry structures are chosen, based on laboratory-built prototypes available in the literature. IPAs are carried out and discussed in order to better understand the influence of the choice of the lateral force distribution pattern on the results. APA is also conducted on the considered models. Finally, all the previous approaches are compared with the results derived from NDA using a fictitious accelerogram with increasing amplitude with time, as well as natural accelerograms with increasing magnitudes. These accelerograms with 
varying intensities are intentionally adopted in order to permit a direct comparison among different seismic analysis methods. Through the discussion about the outcomes from different pushover analyses and NDA applied to simple case-studies, the research contributes to better understand the reliability and limitations of available seismic analysis methods.

\section{LATERAL FORCE DISTRIBUTIONS IN PUSHOVER ANALYSES}

This study presents the comparison among three different seismic analysis methods, namely invariant-force pushover analysis (IPA), adaptive pushover analysis (APA) and NDA.

As for IPA, different force distribution patterns are compared: mass proportional (m-IPA), $i^{\text {th }}$ mode proportional ( $\left.\Phi_{i}-I P A\right), i^{\text {th }}$ mode by mass distribution proportional (Фim-IPA). The m-IPA considers a lateral force distribution pattern proportional to the distribution of mass in the structure. The $\Phi_{i}-I P A$ considers a lateral force distribution proportional to the $i^{\text {th }}$-mode. The displacement of each node of the $\mathrm{i}^{\text {th }}$ mode is obtained through a preliminary eigenvalue analysis. Forces are then applied to all the nodes in the model in proportion to the corresponding $\mathrm{i}^{\text {th }}$-mode displacement shape. The $\Phi$ im-IPA is a force distribution proportional to the $i^{\text {th }}$-mode displacement shape multiplied by the mass distribution. The $\Phi$ im-IPA is determined by multiplying the inertial force at each node, corresponding to its mass, by the $\mathrm{i}^{\text {th }}$-mode normalised displacements. The forces are applied to all the nodes of the structural model as in the $\Phi_{i}$ IPA.

As for APA, the method proposed by Antoniou and Pinho [2004] is considered, in which the loading pattern at each step is incremented to that of the previous step. The load vector $P_{t}$ at a given analysis step $t$ is obtained by adding to the load vector of the previous step $P_{t-1}$ (existing balanced loads) a newly derived load vector increment. This increment is calculated as the product between the current load factor increment $\Delta \lambda_{t}$, the current modal scaling vector $\bar{F}_{t}$ and the nominal load vector $P_{0}$, as presented in the Equation (1).

$P_{t}=P_{t-1+} \Delta \lambda_{t} \bar{F}_{t} P_{0}$

All the previous techniques are compared with NDA, in order to define a full review of nonlinear seismic analysis methods. A simple accelerogram is considered as input for NDA, with increasing amplitude with time, as well as natural accelerograms with increasing magnitudes. These accelerograms with varying intensities have been chosen purposely to get a direct comparison with pushover analysis, in which the structure is loaded incrementally until failure. The Newmark-beta method is used for the integration in the time domain. Constant average acceleration is assumed within each time step, with parameters $\alpha=0.5$ and $\beta=0.25$. 


\section{ANALYSIS OF A FOUR-WALL BUILDING}

\subsection{Description of the model}

A stone masonry one-storey four-wall building is studied (Figure 1a). The model is prepared according to a shaking-table test carried out at the "Laboratório Nacional de Engenharia Civil" (LNEC), in Lisbon, within the European Project "ECOLEADERLIS - Enhancing Seismic Resistance and Durability of Natural Stone Masonry" [Ramos et al. 2005]. The masonry was composed of limestone units and lime mortar joints. The tests included application of a sequence of ground motions intensities up to $0.25 \mathrm{~g}$.

It must be noted that the FEM analyses discussed in this section do not exactly correspond to the experiment carried out in the laboratory. The building shown in Figure $1 a-b$ is only considered as a benchmark case study for the purposes of this research. Some of the material's properties are assumed in the calculations since not all of them were experimentally evaluated by the authors of the research project. The accelerograms adopted for NDA in this study are different from that used in the laboratory shaking-table test. A simple artificial accelerogram with increasing amplitude is considered in order to permit a direct comparison with pushover analyses results. The outcomes of this first NDA are then complemented with those derived from the real natural accelerogram of the 2009 L'Aquila earthquake (Italy), considering it with varying intensities: $100 \%$ (i.e. real occurrence in 2009) and then increasing the magnitude by $200 \%, 300 \%, 400 \%$ and $500 \%$.

The FEM model is seen in Figure 1c. The thickness of the walls is $0.24 \mathrm{~m}$. The density of masonry is $2300 \mathrm{~kg} / \mathrm{m}^{3}$, Young's modulus is $5 \mathrm{GPa}$ and Poisson's ratio is 0.2 . These three values were provided by Ramos et al. [2005]. The compressive strength of masonry is assumed equal to $4 \mathrm{MPa}$, taking into account some available empirical correlations for the specific type of masonry considered [CEN 2005, PIET70 1971]. Tensile strength is taken as $5 \%$ of compressive strength. A smeared crack model is considered with Rankine and Drucker-Prager failure criteria respectively for tension and compression [TNO DIANA 2005]. For the tensile fracture energy, a value of $50 \mathrm{~N} / \mathrm{m}$ is assumed. The structure is modelled with 4-node shell elements. The total number of nodes and elements is 1,275 and 1,197. A Rayleigh damping model is considered, with mass-proportional and stiffness-proportional damping coefficients respectively equal to $a_{0}=5.536$ and $a_{1}=0.0004$. Such values were calibrated in order to ensure reasonable values for the damping ratios, i.e. around $5 \%$, in all the modes contributing significantly to the response. $\mathrm{A}$ time interval of 0.0002 seconds is assumed. Both geometrical and mechanical nonlinearities are considered in the analyses. 
After carrying out the modal analysis of the building, it is possible to detect the first modes with higher translational participation factor in $Y$ direction (NS direction in Figure 1b): mode 3 (participation factor $38 \%$ ), mode 9 (participation factor $7 \%$ ), mode 10 (participation factor $9 \%$ ) and mode 11 (participation factor $8 \%$ ). This set of modes provides a cumulative mass participation factor of $62 \%$.

\subsection{Pushover analyses and NDA}

NDA and pushover analyses of the four-wall building are compared. The analyses are carried out in the $Y$ direction (NS direction in Figure 1b). First, NDA with the artificial accelerogram presented in Figure $2 \mathrm{a}$ is applied. The analysis stops at 1.90 seconds (Figure $2 \mathrm{~b}$ ). The maximum displacement at the top of the southern wall is $2.77 \mathrm{~mm}$ at 1.78 seconds. The relationship between base-shear and displacement at the top of the transversal wall with door is shown in Figure 3.

Comparison is made between three IPAs ( $\left.m-, \Phi_{3^{-}}, \Phi_{3} m-I P A\right)$ and APA (Figure 3 ). The $3^{\text {rd }}$ mode is used for the initial lateral load distribution pattern, instead of the $1^{\text {st }}$ mode since the $3^{\text {rd }}$ shows much higher translational participation factor $(38 \%)$ in the $Y$ direction than the $1^{\text {st }}$ one $(0.6 \mathrm{e}-3 \%)$. This mode is characterised by out-of-plane deformation of transversal walls (Figure $4 a$ ).

As for APA, the load pattern is updated at every increment of $12.5 \mathrm{kN}$ of base shear force (i.e. $V$ $=12.5,25,37.5 \mathrm{kN}$ and so forth). The value of $12.5 \mathrm{kN}$ is equal to $5 \%$ of the weight of the entire structure. Once the model reaches the corresponding load increment, eigenvalue analysis is run. The load pattern is then updated according to the shape of the mode with higher participation factor at that step of the analysis. In this analysis, the load pattern has been updated seven times.

The control node at the top of the transversal wall with door is considered. When the base shear force vs. displacement relations are compared, the curve obtained from m-IPA is in better agreement with the NDA envelope than the $\Phi_{3}$-IPA and APA, although the latter two predict closer displacement capacity (Figure 3 ). In fact, the capacity curve of APA is almost equal to that of $\Phi_{3}$-IPA.

The principal positive strain contours at the ultimate state from the pushover analyses are compared with those from NDA at 1.78 seconds (Figure 4b). In the post-processing of the results from the analyses, the location of damage is recognised as a high level of principal strain values that denote the opening of cracks, according to the smeared crack approach [Pelà et al. 2013c]. The m-IPA shows damage in the longitudinal wall close to the corners of the two openings (Figure 5a). On the other hand, $\Phi_{3}$-IPA and $\Phi_{3} \mathrm{~m}$-IPA show concentration of damage in 
the southern wall over the door (Figure $5 \mathrm{~b}-\mathrm{c}$ ). The APA analysis shows a very similar damage to the $\Phi_{3}$-IPA (Figure $5 \mathrm{~d}$ ). On the other hand, the NDA is able to represent both damage patterns (Figure $4 b$ ), i.e. cracking over the door and at the corners of the windows.

The different force distribution patterns used in the pushover analyses are also compared (Figure 6). They are all normalised so that the sum of the forces is equal to $99 \mathrm{kN}$ which is around the value of the maximum load capacity of $\Phi_{3}$ IPA and APA. The m-IPA distributes forces rather uniformly along the height, according to mass distribution. In fact, the magnitude of forces is lower at around the height of $2 \mathrm{~m}$, due to the openings in the walls. On the other hand, both the $\Phi_{3}$ - and $\Phi_{3}$ m-IPAs show similar patterns with higher concentration of forces in the upper part of the structure, in disagreement with m-IPA distribution. As for NDA, two lateral force distribution patterns are presented. Firstly, the force pattern at 0.41 seconds of timehistory is considered. At this moment, the model experiences a base shear force equal to $99 \mathrm{kN}$ for the first time in the analysis. Secondly, the force distribution pattern at the last peak of the time history at 1.78 seconds is considered (see Figure 2). The former is named NDA in Figure 6 while the latter is named last peak (NDA). A remarkable agreement is observed between NDA and m-IPA. However, the NDA lateral force distribution at last peak shows slightly higher forces in the upper part of the building than in the m-IPA. NDA force distributions do not change so much during the development of the analysis. Figure 6 shows APA force distribution pattern at the ultimate state. The initial shape of the APA force distribution is equal to that of $\Phi_{3}$-IPA. When these two force patterns are compared, their lower parts (up to $2.5 \mathrm{~m}$ ) are very similar.

Finally, additional NDAs were carried out by considering the natural accelerogram of the earthquake occurred in L'Aquila (Italy) in 2009 (Figure 7a). Different NDAs were carried out by considering the input record with 100\% magnitude (i.e. real occurrence in 2009) and then by amplifying it by $200 \%, 300 \%, 400 \%$ and $500 \%$. The intensity of the natural accelerogram was progressively amplified in order to obtain further comparisons with the previously obtained pushover capacity curves. Figure $7 \mathrm{~b}-\mathrm{c}$ show the obtained time-histories for displacement and base shear. The NDAs lasted all the duration of the earthquake, except that with $500 \%$ magnitude which stopped at 2.32 seconds. Figure 8 presents the comparison between the capacity curves from pushover analyses and the maxima from NDAs in terms of displacement and base shear. As shown, the NDAs maxima progressively follow the m-IPA capacity curve, even though the NDA with $500 \%$ magnitude accelerogram provides a higher ultimate displacement $(2.78 \mathrm{~mm})$ than that of $\mathrm{m}$-IPA.

The maximum response values obtained from NDAs (with artificial and natural accelerograms) and pushover analyses are summarized in Table 1. As shown, the m-IPA provides the shear 
capacity closest to those predicted by NDAs, even though it underestimates the ultimate displacement capacity.

\section{ANALYSIS OF TWO-WALL BUILDING WITH CROSS VAULT}

\subsection{Description of the model}

A reduced-scale two-wall building with cross vault is analysed using different nonlinear seismic approaches. This structural typology was analysed by the Research on Restoration of the Hellenic Ministry of Culture (DTRR/HMC) in collaboration with the Laboratory of Earthquake Engineering of National Technical University of Athens (LEE/NTUA) in 2007 [Miltiadou-Fezans 2008]. The reduced-scale building consists of a cross vault which rests over two parallel walls with small openings. The walls are composed of three-leaf stone masonry. The external leafs are composed of travertine stones and lime mortar, whereas the internal leaf is composed of rubble stones and lime mortar. The vault is composed of solid bricks and lime mortar. Due to the size of the shaking simulator $\left(4 \times 4 \mathrm{~m}^{2}\right)$, the scale of the building was 2:3 with respect of the prototype structure (Figure 9a). The plan of the model building is $2.71 \times 2.60 \mathrm{~m}^{2}$. The height of the walls is $2.60 \mathrm{~m}$ and the total height of model is approximately equal to $2.85 \mathrm{~m}$. The thickness of the walls is $0.45 \mathrm{~m}$, whereas the thickness of the vault is $0.20 \mathrm{~m}$.

The FE model is prepared using 4-node curved quadrilateral shell elements. The total number of nodes and element is 2,474 and 2,956 (Figure 9b). The mechanical parameters of masonry are determined on the basis of the experiments carried out on the materials [Vintzileou et al. 2008]. The input parameters required by the model that were not experimentally evaluated have been assumed using reference values from available standards for this specific type of masonry. The density is $2000 \mathrm{~kg} / \mathrm{m}^{3}$ for stone masonry and $1800 \mathrm{~kg} / \mathrm{m}^{3}$ for brick masonry, the compressive strength is $4 \mathrm{MPa}$, Young's modulus is $2 \mathrm{GPa}$, the Poisson's ratio is 0.2 . Tensile strength is taken as $5 \%$ of compressive strength. For the tensile fracture energy, a value of 50 $\mathrm{N} / \mathrm{m}$ is assumed. The same failure criteria as ones presented in Section 3.1 are considered, namely Rankine in tension and Drucker-Prager in compression. For NDA, the same Rayleigh damping model as in Section 3.1 is applied, in order to ensure 5\% damping ratio in all the modes contributing significantly to the response, with $a_{0}=4.2638$ and $a_{1}=0.0005$. Time intervals of 0.00063 seconds are considered.

After carrying out the modal analysis of the building, it is possible to detect the first modes with higher translational participation factor in $\mathrm{Y}$ direction (Figure 9b): mode 1 (participation factor $67 \%$ ), mode 6 (participation factor 15\%) and mode 21 (participation factor $5 \%$ ). This set of modes provides a cumulative mass participation factor of $87 \%$. 


\subsection{Pushover analyses and NDA}

The analyses are carried out in the transversal $(Y)$ direction (Figure 9b). Firstly, NDA is carried out with the simple artificial accelerogram presented in Figure 10a. The analysis stops at 0.846 seconds. The absolute maximum displacement is $11.02 \mathrm{~mm}$ at the end of the NDA (Figure 10b). The relationship between base-shear and displacement at the top of the wall is shown in Figure 11.

IPAs are carried out by comparing three invariant force distribution patterns (m-IPA, $\Phi_{1}$-IPA and $\left.\Phi_{1} \mathrm{~m}-\mathrm{IPA}\right)$. The first mode deformed shape is shown in Figure12a and it is characterised by outof-plane movement of two parallel walls.

As for APA, the same procedure explained in Section 3.3 is applied. The load pattern is updated at every increment of $7.0 \mathrm{kN}$ of base shear force (i.e. $V=7,14,21 \mathrm{kN}$ and so forth). The value of $7.0 \mathrm{kN}$ is equal to $5 \%$ of the weight of the entire structure. In this analysis, the load pattern has been updated seven times.

When the load-displacement curves from pushover analyses and NDA are compared, m-IPA provides a curve with a similar shape to the NDA envelope (Figure 11). The m-IPA shows closer load capacity to NDA than the other IPA methods. On the other hand, the three IPAs show much lower displacement capacity than NDA. The curve of $\Phi_{1}$ m-IPA passes close to that of $\Phi_{1}$ IPA. APA shows almost an identical curve with that of $\Phi_{1}$-IPA.

The principal positive strain contours from NDA and pushover analyses are compared. They show similar damage patterns, showing cracks in the vault and at the bottom of the model, although NDA presents higher damage intensity (Figure 12b, Figure 13).

The different force distribution patterns used in the pushover analyses are also compared (Figure 14), as done in Section 3.2. They are all normalised so that the sum of the forces is equal to $53.0 \mathrm{kN}$, which is the value of the load capacity of $\Phi_{1}$-IPA and APA. The m-IPA shows an increase of lateral forces' magnitude at the upper part of the structure, due to the existence of the cross-vault. The $\Phi_{1}$ IPA shows even higher magnitude of forces in the upper part of the structure. The $\Phi_{1} m$-IPA also shows similar shape of the force distribution pattern to the $\Phi_{1}$-IPA, but with slightly higher values in the lower part of the structure and slightly lower in the upper part. As for NDA, two lateral force distribution patterns are presented as in Section 3.2. Firstly, the force pattern at 0.55 seconds of time-history is considered. This is the moment when the model goes through the base shear force equal to $53 \mathrm{kN}$ for the first time. Secondly, the force distribution pattern of the last peak at 0.83 seconds is considered. The NDA force distribution at 
0.55 seconds shows a similar shape to m-IPA. The force distribution at the last peak of NDA shows higher forces in the upper part of the structure than those at at 0.55 seconds. The initial force distribution pattern of APA is equal to that of $\Phi_{1}-I P A$ and then evolves until reaching that shown in Figure 14. These two force patterns (APA and $\Phi_{1}-$ IPA) show a similar shape in the upper apart (from $1.75 \mathrm{~m}$ above). In the lower part (up to $1.75 \mathrm{~m}$ ), the force distribution pattern of APA shows a shape similar to that of $\mathrm{m}$-IPA, in spite of lower magnitude.

Finally, additional NDAs were carried out by considering the natural accelerogram of the earthquake occurred in Irpinia (Italy) in 1980 (Figure 15a). Different NDAs were carried out by considering the input record with $100 \%$ magnitude (i.e. real occurrence in 1980) and then by amplifying it by $200 \%, 300 \%$ and $400 \%$. The intensity of the natural accelerogram was progressively amplified in order to obtain further comparisons with the previously obtained pushover capacity curves. Figure 15b-c show the obtained time-histories for displacement and base shear. The NDAs lasted all the duration of the earthquake, except that with $400 \%$ magnitude which stopped at 4.48 seconds. Figure 16 presents the comparison between the capacity curves from pushover analyses and the maxima from NDAs in terms of displacement and base shear. As shown, the NDAs maxima progressively follow the m-IPA capacity curve, even though the NDA with $400 \%$ magnitude accelerogram provides a higher ultimate displacement $(5.04 \mathrm{~mm})$ than that of $\mathrm{m}-\mathrm{IPA}$.

The maximum response values obtained from NDAs (with artificial and natural accelerograms) and pushover analyses are summarized in Table 2. The m-IPA shows closer load capacity to NDAs than $\Phi_{1}-$ IPA, APA and $\Phi_{1}$ m-IPA.

\section{DISCUSSION}

Two single-storey masonry buildings have been analysed with the aim of comparing different pushover analysis methods. The first building is composed of four walls and lacks of a rigid floor diaphragm. The second building is made of two parallel walls that support a masonry crossvault, i.e. a rather heavy type of floor. The two selected cases are simple basic systems that can be often found in historical masonry construction. The comparison has been made among nonlinear dynamic analyses (NDAs) with artificial and natural accelerograms, invariant-force pushover analysis (IPA) and adaptive pushover analysis (APA).

The base shear force vs. displacement relations from the IPAs were compared with those from NDAs. The capacity curve of m-IPA has shown to be very similar to the upper bound envelope of shear force vs. displacement cycles of NDA with artificial accelerogram. In the same way, the m-IPA capacity curve has shown to follow quite closely the maxima obtained from the NDAs 
with natural accelerograms with increasing magnitude. The m-IPA has shown closer load capacity to NDAs than the other two IPA methods $\left(\Phi_{1^{-}}, \Phi_{1} \mathrm{~m}-\mathrm{IPA}\right)$. On the other hand, the three IPAs (m-, $\left.\Phi_{1-}, \Phi_{1} \mathrm{~m}-I P A\right)$ have shown lower displacement capacity than NDAs. In the application of IPAs to the four-wall structure, a remarkable influence of the lateral force distribution on the damage patterns has been observed. However, none of the damage patterns from pushover analyses has coincided with that obtained from NDA.

For the two structures analysed, lateral force distribution patterns derived from IPAs and NDA have been also compared. In the elastic range, the lateral distribution patterns from NDA with artificial accelerogram are rather similar to the m-IPA ones. Once the structure has reached the nonlinear range, the NDA distribution of forces presents higher magnitudes in the upper part of the structure than in the m-IPA. The $\Phi_{1}$-IPA force distribution pattern has shown more concentration of lateral forces in the upper part of the structure than in NDA in the nonlinear stage. This observation on lateral force distribution patterns explains the reason the $\Phi_{1}$ IPA causes smaller resistance to the structure than the m-IPA.

APA has been applied to the two models. The first mode proportional lateral load distribution has been considered for the initial step. The lateral load pattern has been updated seven times at predefined load levels of $5 \%$ of the weight of the entire structure. For both structures, APA has shown similar capacities and damage patterns to the $\Phi_{1}$-IPA. Both load and displacement capacities evaluated by APA have resulted lower than those of NDA. As expected, the $1^{\text {st }}$-mode proportional force distribution pattern has shown high concentration of the force in the upper part of the two structures.

A significant difference between the two structures analysed lays in the presence of a rigid diaphragm in the second one. The pushover analyses of the four-wall building without rigid diaphragms have provided results different from those derived from NDA, especially in terms of failure mechanisms. The damage has concentrated over localized portions of the structure, leading to strong underestimation of the capacity of the building. NDA has provided a more complete description of the types of failure in the structure, i.e. the in-plane shear and the outof-plane ones. In turn, m-IPA has represented mainly the former, whereas all the other pushover analyses have only modelled the latter.

The adoption in NDAs of an artificial accelerogram with increasing amplitude or natural accelerograms with different magnitudes, has been useful to directly compare the NDAs results with the pushover capacity curves. In fact, both types of the adopted accelerograms have excited increasingly the structure until bringing it to failure. Therefore both NDA methods have constituted the ideal dynamic counterparts of pushover analysis, where the structure is pushed 
by static-equivalent seismic forces until failure. In this way, a direct and rigorous comparison between NDAs and pushover outcomes has been possible. The NDAs with artificial and natural accelerograms have all shown a clear correspondence with the m-IPA capacity curves. Whenever the NDA has lasted the whole duration of the earthquake record, i.e. for low-medium magnitudes, the NDA maxima have shown to agree quite well with the trend of the m-IPA capacity curve. On the other hand, whenever the magnitude of the accelerogram has been high enough to interrupt the NDA before the end of the earthquake record, the NDAs have always provided higher ultimate displacement values than pushover analyses, although the shear capacity has resulted very similar. It is worth mentioning, however, that in this last case of highmagnitude input accelerograms able to stop the analysis before the end of the record, it is not trivial to evaluate the maximum displacement capacity of the structure. In fact, after having reached its maximum shear capacity, the failure mechanism is activated and so the displacements progressively evolve until the model's collapse and thus the NDA interruption. In this research, for NDAs with high magnitude input records bringing the structure to early collapse, the ultimate displacement capacity has been considered as that reached when the structure experiences the maximum shear capacity during the shaking motion.

The study, as a first approach to the problem, has focused on simple case studies with singlestorey masonry buildings. More complex structural forms have to be considered in the future research in order to obtain meaningful comparisons between NDA and pushover results, for instance by considering more complex models such as multiple bay single storey buildings and multi-storey systems.

\section{CONCLUSIONS}

The paper has presented a review of seismic assessment procedures, including different pushover analysis techniques and NDA. For the IPA, different lateral force distribution patterns have been considered, i.e. mass-proportional (m-IPA), first-mode proportional $\left(\Phi_{1}-I P A\right)$ and firstmode by mass proportional ( $\left.\Phi_{1} \mathrm{~m}-\mathrm{IPA}\right)$. The m-IPA has shown a load capacity closer to NDA analysis than the $\Phi_{1}-$ IPA. The $\Phi_{1}$ m-IPA has shown similar results to $\Phi_{1}-$ IPA. However, the IPAs have substantially underestimated the displacement capacity in comparison with NDA. The $\Phi_{1-}$ IPA and $\Phi_{1}$ m-IPA have provided much lower shear capacity than NDA and m-IPA. They have also underestimated the displacement capacity if compared to NDA, and have displayed different failure mechanisms. In general, the IPAs and NDA have not shown an acceptable agreement in damage patterns and failure mechanisms. These considerations may indicate certain limitations of IPA compared to NDA. 
An advanced pushover analysis based on an adaptive procedure (APA) has been also considered. In this case, it has been found that the results are highly influenced by the choice of the initial force distribution pattern and the updating method of the force distribution. The analyses conducted on two building prototypes with predominant first mode have not proved the capability of APA for these specific case-studies and the results have been practically similar to those derived from $\Phi_{1}$ IPA.

As expected, the type of floor in the masonry building has shown to be very influent on the results provided by pushover analysis. The two investigated buildings have presented two recurrent cases in historical masonry buildings, i.e. absence of rigid diaphragm and vaulted system. In the first case, the building does not present a global response and this has been adequately represented by pushover analyses, which have been able to simulate local mechanisms and damage patterns. In the second case, the stiffer and heavier vaulted floor has led to similar damage patterns both in pushover analyses and NDA, even though the former ones have underestimated both the shear and displacement capacities.

In spite of the limitations observed in the present research, m-IPA has shown to be the most reliable pushover method for the analysis of the considered building prototypes. The force distribution patterns from NDA have resulted rather similar to that assumed in m-IPA, leading to a good agreement in the evaluation of maximum shear capacity. In general, m-IPA underestimates the ultimate displacement capacity derived from NDA, as also found in recent studies for other masonry structures [Pelà et al 2013b]. All the aforementioned results show that m-IPA can be considered as an acceptable method for the seismic assessment of simple structural systems built in masonry. However, for more complex masonry structures NDA still constitutes a more accurate method than m-IPA, as also demonstrated by recent studies [Endo et al. 2015].

NDA requires rather high computational effort unless the analysis is run by a powerful computer. For these reason, pushover analyses are often preferred by analysts. However, the present study has revealed some of the limitations of these seismic analysis methods. Such limitations should be always recognized whenever the analysis of a masonry building is carried out. In addition, it would be advisable to combine distinct analysis methods to overcome the limitations of each one. Although this paper considers a limited set of case studies, it is believed that the outcomes of this research may be of interest for further seismic assessments of more complex systems and also of historical masonry structures. 


\section{ACKNOWLEDGEMENTS}

This research has received the financial support from the MINECO (Ministerio de Economia y Competitividad of the Spanish Government) through the MULTIMAS project (Multiscale techniques for the experimental and numerical analysis of the reliability of masonry structures, ref. num. BIA2015-63882-P) and the MICROPAR project (Identification of mechanical and strength parameters of structural masonry by experimental methods and numerical micromodelling, ref. num. BIA2012-32234).

\section{REFERENCES}

Albanesi, T. Biondi, S. and Petrangeli, M. [2002] "Pushover analysis: An energy based approach," In Proc. of the Twelfth European Conference on Earthquake Engineering, London, United Kingdom, Paper No. 605.

Antoniou, S. and Pinho, R. [2004] "Development and verification of a displacement-based adaptive pushover procedure," Journal of Earthquake Engineering 8(05), 643-661.

Aydinoğlu, M.N. [2003] "An incremental response spectrum analysis procedure based on inelastic spectral displacements for multi-mode seismic performance evaluation," Bulletin of Earthquake Engineering 1(1), 3-36.

Betti, M. and Vignoli, A. [2011] "Numerical assessment of the static and seismic behaviour of the basilica of Santa Maria all'Impruneta (Italy)," Constr Build Mater 25(12), 4308-4324.

Bracci,. J.B.and Kunnath, S.K. and Reinhorn, A.M. [1997] "Seismic performance and retrofit evaluation of reinforced concrete structures," Journal of Structural Engineering, 123, 3-10.

Casolo, S. and Uva, G. [2013] "Nonlinear analysis of out-of-plane masonry façades: full dynamic versus pushover methods by rigid body and spring model," Earthq Eng Struct D 42, 499-521.

Chopra, A.K. and Goel, R.K. [2002] "A modal pushover analysis procedure for estimating seismic demands for buildings," Earthquake Engineering \& Structural Dynamics, 31(3), 561582.

Chopra, A.K. and Goel, R.K. [2004] "A modal pushover analysis procedure to estimate seismic demands for unsymmetric-plan buildings". Earthquake engineering \& structural dynamics, 33[8], 903-927.

Endo, Y. Pelà, L. Roca, P. da Porto, F. and Modena, C. [2015] "Comparison of seismic analysis methods applied to a historical church struck by 2009 L'Aquila earthquake," Bul Earthq Eng DOI :10.1007/s10518-015-9796-0.

Fajfar, P. [2000] "A nonlinear analysis method for performance based seismic design," Earthq Spectra 16[3], 573-592.

Fajfar, P. Kilar V, Marusic, D. Perus, I. and Magliulo, G. [2005] "The extension of the N2 method to asymmetric buildings," Proceedings of the 4th European workshop on the seismic behaviour of irregular and complex structures

Federal Emergency Management Agency [2004] "Improvement of inelastic seismic analysis procedures," FEMA 440, Federal Emergency Management Agency, Washington, D.C. 
Galasco, A. Lagomarsino, S. and Penna, A. [2006] "On the use of pushover analysis for existing masonry buildings," Proceedings of first european conference on earthquake engineering and seismology (a joint event of the 13th ECEE and 30th general assembly of the ESC) 3-8.

Ivancic, S.R. Briceno, C. Marques, R. Aguilar, R. Perucchio, R. and Vargas, J. [2014] "Seismic assessment of the St. peter apostle church of Andahuaylillas in Cusco, Peru," SAHC2014 - 9th International Conference on Structural Analysis of Historical Constructions, Mexico City: 2014

Jan, T.S. Liu, M.W.and Kao, Y.C. [2004] "An upper bound pushover analysis procedure for estimating the seismic demands of high rise buildings," Engineering Structures, 26, 117-128.

Krawinkler, H. [1995] "New trends in seismic design methodology,". In: Proceedings of 10th European Conference on Earthquake Engineering, Vienna, Austria, vol.2, Rotterdam, AA Balkema, 821-30.

Kreslin, M. and Fajfar, P. [2012] "The extended N2 method considering higher mode effects in both plan and elevation," Bul Earthq Eng,10(2), 695-715.

Lagomarsino. S. Cattari, S. Degli Abbati, S. and Ottonelli, D. [2014] "Seismic assessment of complex monumental buildings in aggregate: the case study of Palazzo del Podestà in Mantua (Italy)," SAHC2014 - 9th International Conference on Structural Analysis of Historical Constructions, Mexico City.

Lourenço, P.B. Mendes, N. Ramos, L.F. and Oliveira, D.V. [2011] "Analysis of Masonry Structures Without Box Behaviour," Int J Archit Herit 5, 369-382.

Lourenço, P.B. Trujillo, A. Mendes, N. and Ramos, L.F. [2012] "Seismic performance of the St. George of the Latins church: Lessons learned from studying masonry ruins," Eng Struct 40:501518.

Magliulo, G. Maddaloni, G. and Cosenza, E. [2012] "Extension of N2 method to plan irregular buildings considering accidental eccentricity," Soil Dynamics and Earthquake Engineering, 43, 69-84.

Milani, G. Acito, M. Chesti, C. Di Francesco, C. and Martines, G. [2014] "A multidisciplinary insight into the collapse causes of the masonry clock tower and castle in Finale Emilia, Italy," SAHC2014 - 9th International Conference on Structural Analysis of Historical Constructions, Mexico City.

Miltiadou-Fezans, A. [2008] "A multidisciplinary approach for the structural restoration of the Katholikon of Dafni Monastery in Attica Greece," Structural Analysis of Historical ConstructionsSAHC08 Bath, the UK, 71-87.

Mwafy, A.M. and Elnashai, A.S. [2001]. "Static pushover versus dynamic collapse analysis of RC buildings," Engineering structures 23(5), 407-424.

Papanikolaou, V.K. and Elnashai, A.S. [2005] "Evaluation of conventional and adaptive pushover analysis I," Methodology. Journal of Earthquake Engineering 9(06), 923-941.

Pelà, L. Aprile, A. and Benedetti, A. [2009] "Seismic assessment of masonry arch bridges," Eng Struct 31(8), 1777-88.

Pelà, L. Benedetti, A. Aprile, A. and Mangoni, E. [2013a] "Seismic assessment of the Milano Centrale railway station," Int J Archit Herit 7, 609-627. 
Pelà, L. Aprile, A. and Benedetti, A. [2013b] "Comparison of seismic assessment procedures for masonry arch bridges," Constr Build Mater 38, 381-394.

Pelà, L. Cervera, M. and Roca, P. [2013c] "An orthotropic damage model for the analysis of masonry structures," Constr Build Mater 4, 957-967.

Penna, A. Rota, M. Mouyiannou, A. and Magenes, G. [2013] "Issues on the use of time-history analysis for the design and assessment of masonry structures," In Proc. 4th ECCOMAS Thematic Conference on Computational Methods in Structural Dynamics and Earthquake Engineering, COMPDYN 2013, Kos Island, Greece.

Reinhorn, A. [1997] "Inelastic techniques in seismic evaluations. in Seismic Design Methodologies for the Next Generation of Codes," Fajfar P, and Krawinkler H, eds, Bled, Slovenia.

Ramos, L.F. Lourenço, P.B. and Costa, A.C. [2005] "Operational modal analysis for damage detection of a masonry construction," Proceeding in International Operational Modal Analysis Conference, 1, Copenhagem, Aalborg, Aalborg University, 495-502.

Roca, P. Cervera, M. Pelà, L, Clemente, R. and Chiumenti, M. [2013] "Continuum FE models for the analysis of Mallorca Cathedral," Engineering Structures 46, 653-670.

Saloustros, S. Pelà, L. Roca, P. and Portal, J. [2015] "Numerical analysis of structural damage in the church of the Poblet Monastery," Engineering Failure Analysis, 48, 41-61.

Simões, A. Bento, R. Cattari, S. Lagomarsino, S. [2014] "Seismic performance based assessment of "Gaioleiro" buildings," Engineering Structures, 80, 486-500. 


\section{TABLES}

Table 1 - Comparison of maximum responses from different seismic analysis methods applied to the four-wall building.

\begin{tabular}{lcl}
\hline \multicolumn{1}{c}{ Assessment tool } & $\begin{array}{c}\text { Displacement [mm] } \\
{[\text { longitudinal wall] }}\end{array}$ & Base shear [kN] \\
\hline NDA (artificial) & 2.77 & 356.0 \\
NDA (natural) $\mathbf{5 0 0 \%}$ & 2.78 & 313.6 \\
NDA (natural) $\mathbf{4 0 0 \%}$ & 1.47 & 299.7 \\
NDA (natural) 300\% & 1.13 & 253.0 \\
NDA (natural) 200\% & 0.59 & 129.2 \\
NDA (natural) 100\% & 0.26 & 65.0 \\
$\Phi_{3}$ m-IPA & 1.86 & 107.0 \\
$\Phi_{3}$-IPA & 2.28 & 99.9 \\
m-IPA & 1.76 & 306.0 \\
APA & 2.38 & 99.2 \\
\hline
\end{tabular}

Table 2 - Comparison of maximum responses from different seismic analysis methods applied to the two-wall building with vault.

\begin{tabular}{lcl}
\hline \multicolumn{1}{c}{ Assessment tool } & $\begin{array}{c}\text { Displacement [mm] } \\
\text { [top of the wall] }\end{array}$ & Base shear [kN] \\
\hline NDA (artificial) & 11.6 & 88.7 \\
NDA (natural) 400\% & 5.04 & 84.9 \\
NDA (natural) 300\% & 2.86 & 71.3 \\
NDA (natural) 200\% & 1.66 & 51.5 \\
NDA (natural) 100\% & 0.74 & 24.2 \\
Ф1m-IPA & 3.49 & 57.5 \\
Ф1-IPA & 3.71 & 53.0 \\
m-IPA & 3.17 & 80.4 \\
APA & 3.58 & 53.1 \\
\hline
\end{tabular}




\section{FIGURES}

(a)
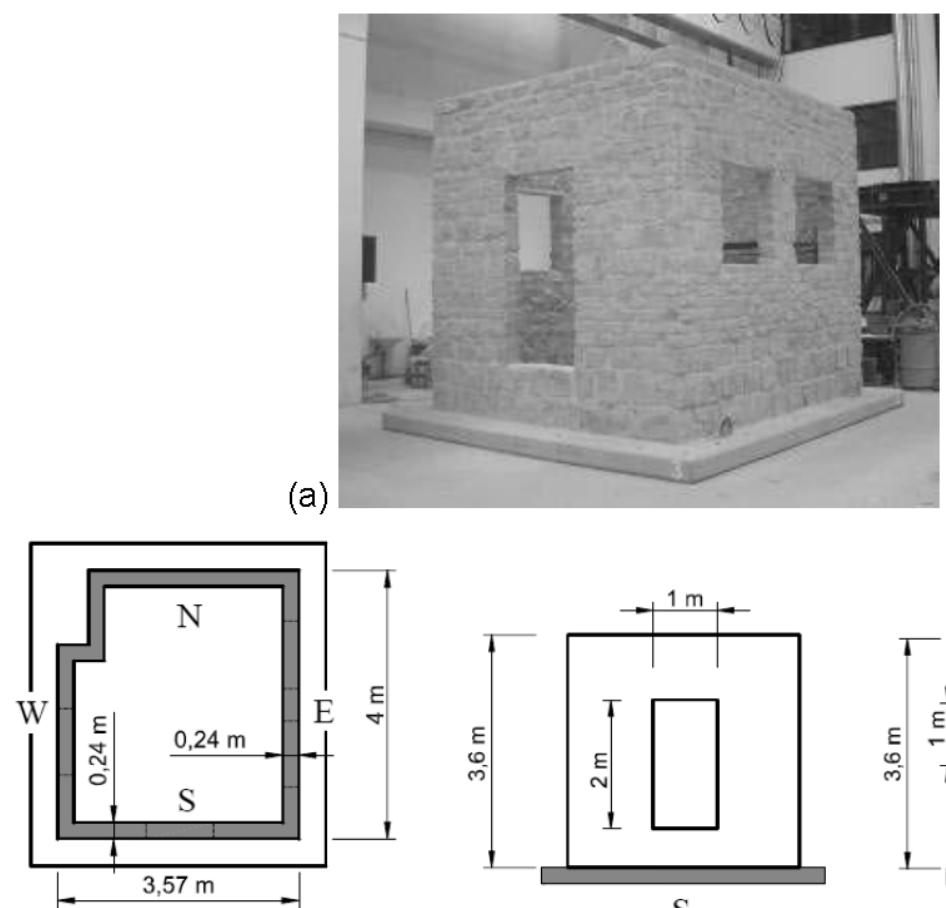

(b)

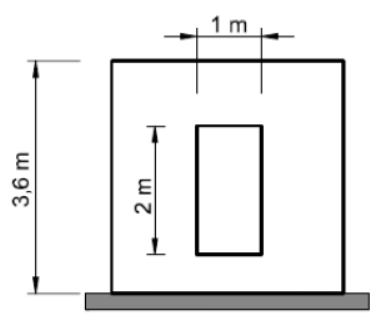

$\mathrm{S}$

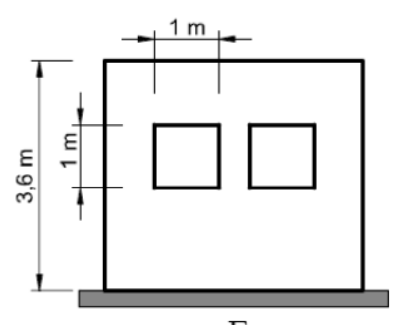

$\mathrm{E}$

(c)

Figure 1 - Reduced-scale four-wall building [Ramos et al. 2005]: (a) before testing in the laboratory, (b) geometrical dimensions and (c) finite element model adopted. 


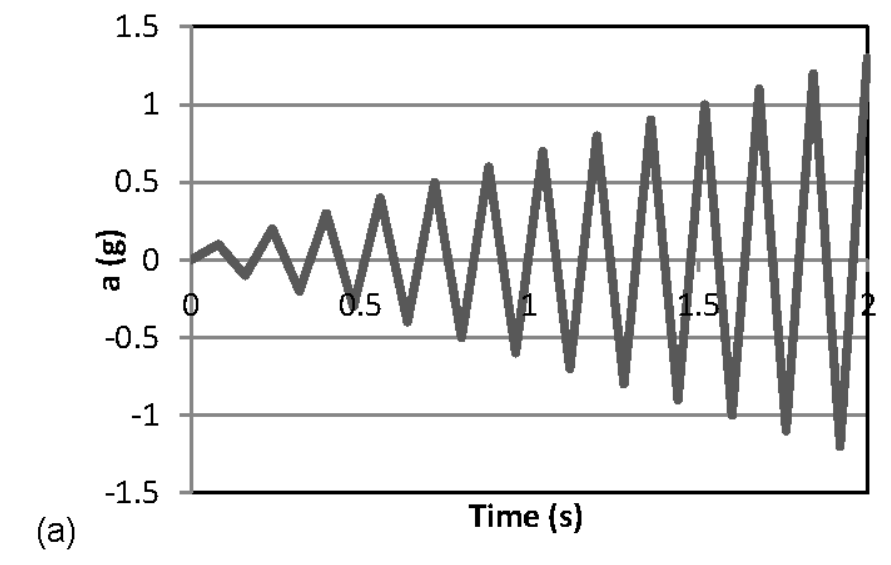

(b)

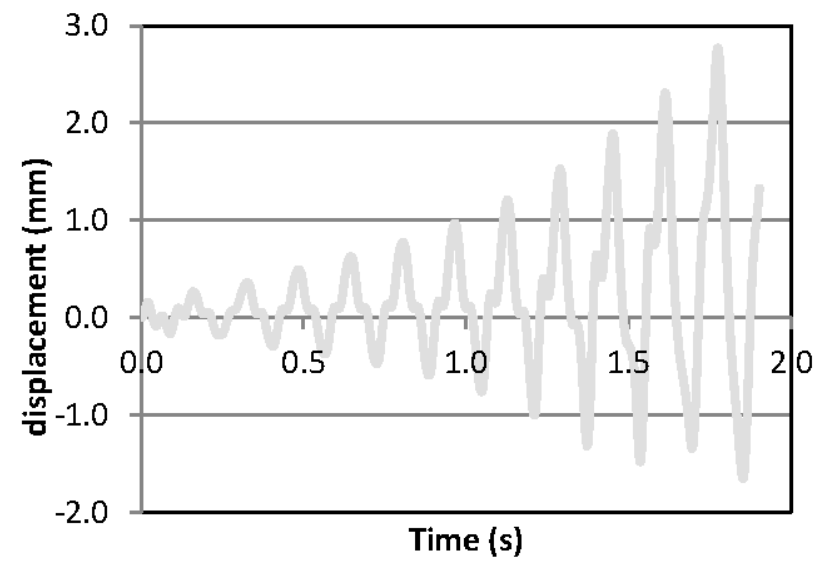

Figure 2 - NDA of the four-wall building: (a) adopted simple artificial accelerogram and (b) time history of the displacement at the top of the wall with door. 


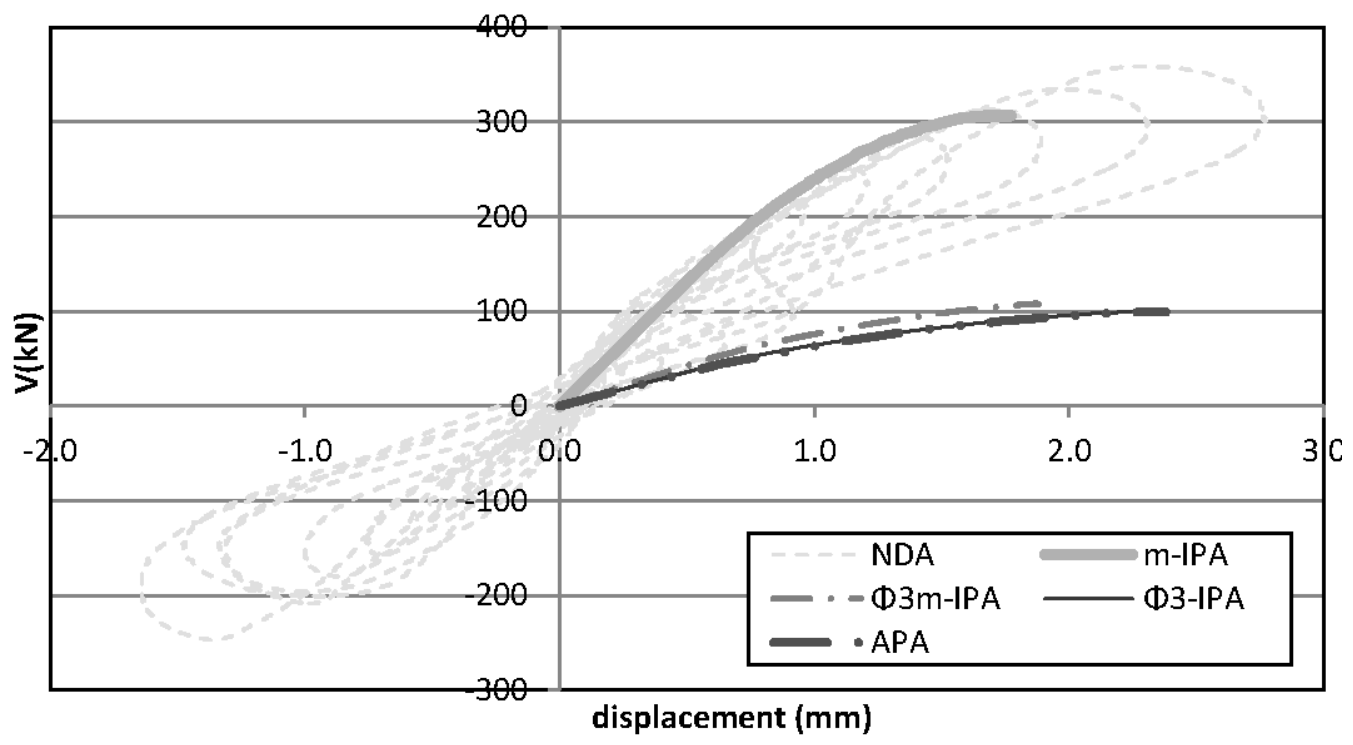

Figure 3 - Four-wall building: base-shear vs. displacement curves for different pushover analyses and NDA with artificial accelerogram. 
(a)

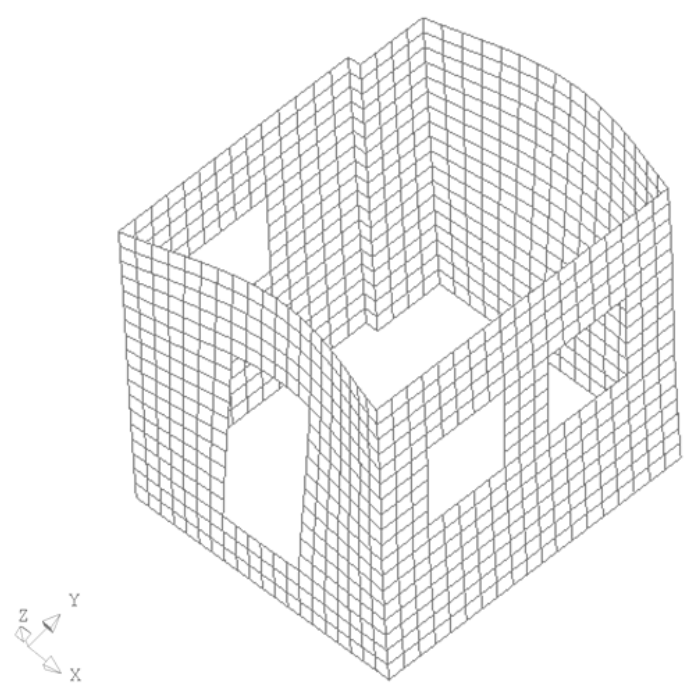

(b)

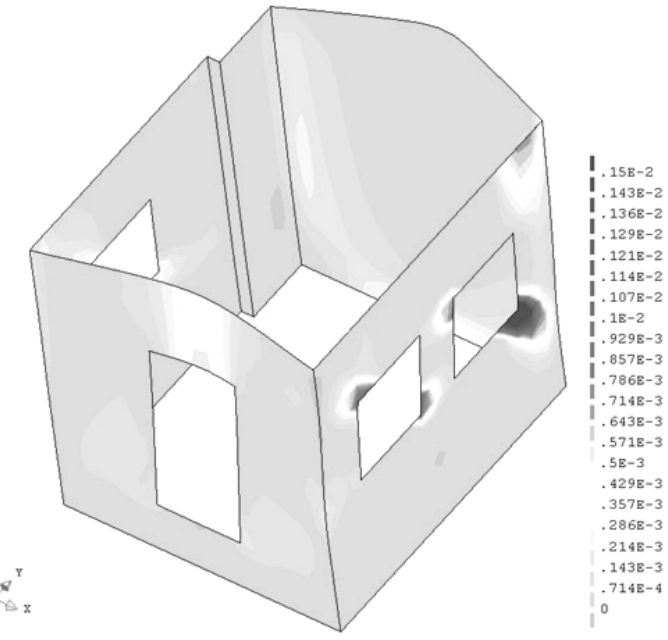

Figure 4 - Deformed shape of the $3^{\text {rd }}$ mode in the $Y$ direction (a) and principal strain contours from NDA with artificial accelerogram at 1.78 seconds (b). 
(a)

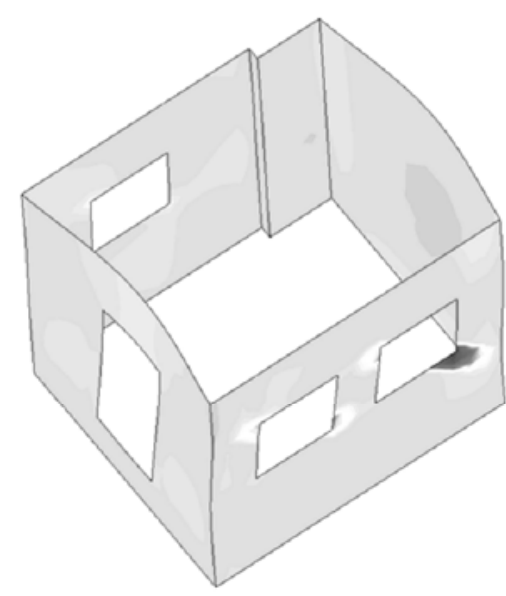

(b)

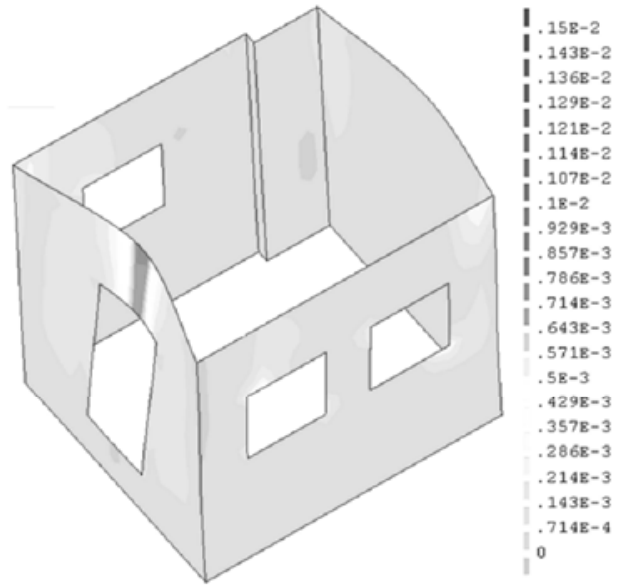

(c)

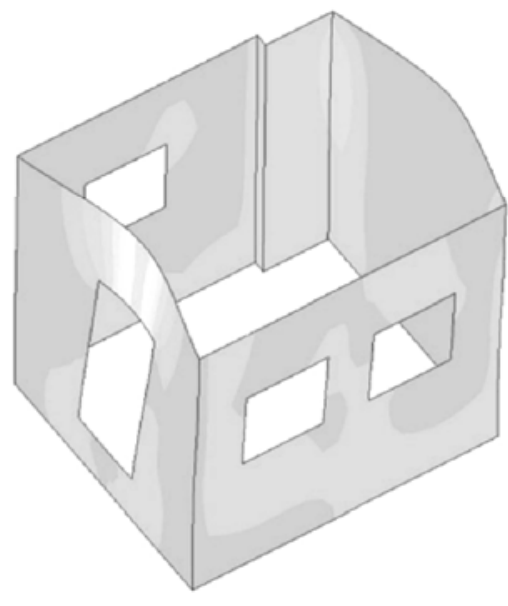

(d)

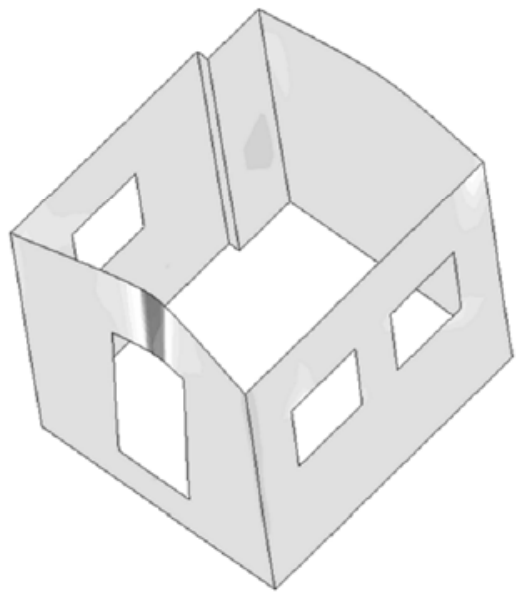

Figure 5 - Principal strain contours at the ultimate state for: (a) m-IPA, (b) $\Phi_{3}-I P A,(c) \Phi_{3} m$-IPA and (d) APA. 


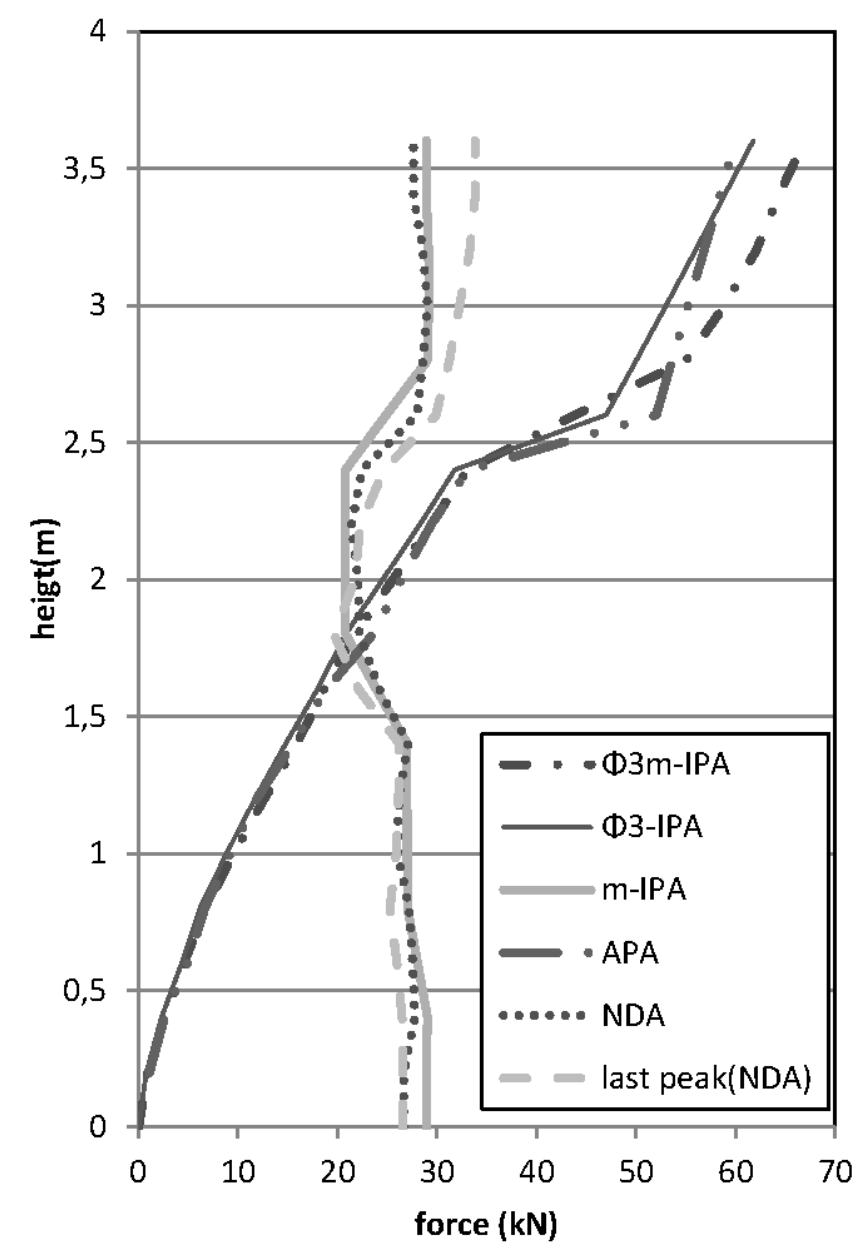

Figure 6 - Four-wall building: comparison of lateral force distribution patterns among pushover analyses and NDA with artificial accelerogram. 


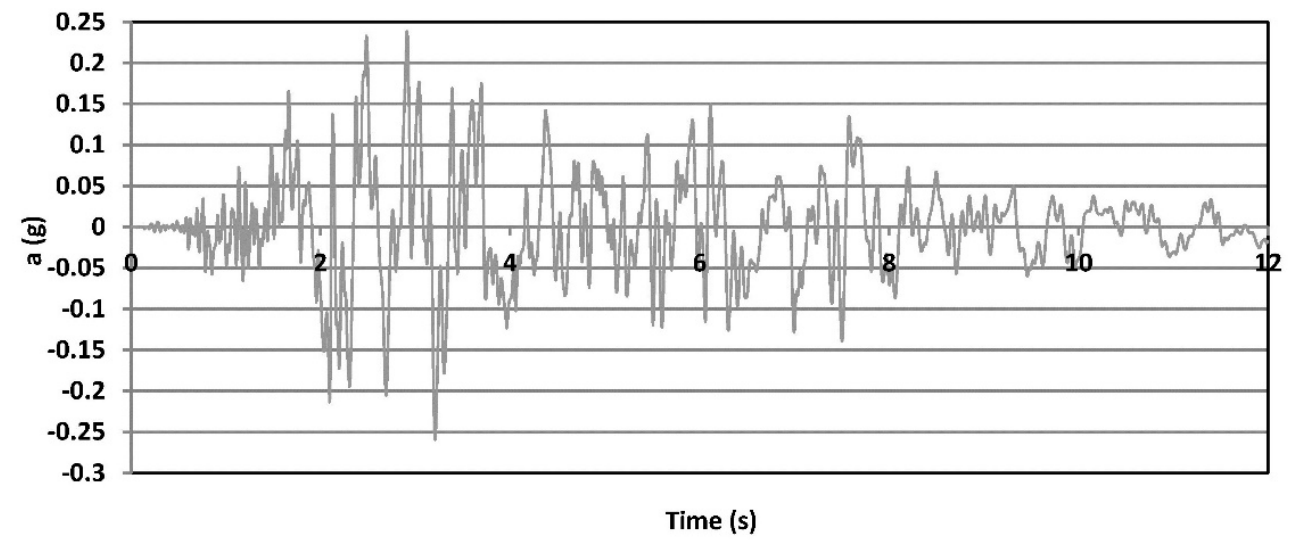

(a)
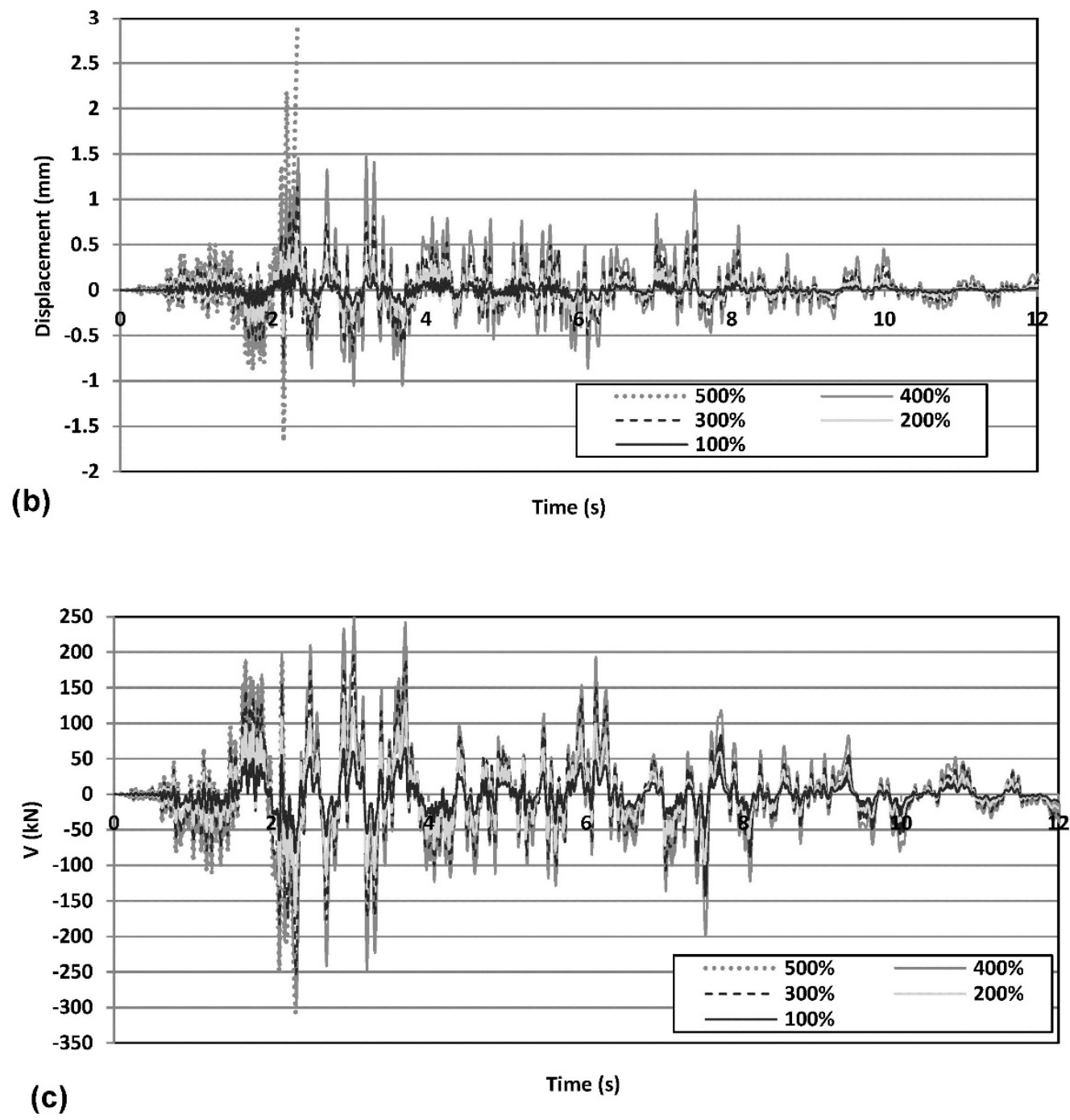

Figure 7 - NDA of the four-wall building: natural accelerogram of 2009 L'Aquila earthquake (a), time-histories of displacement (b) and base shear (c) for different magnitudes (100\%-500\%). 


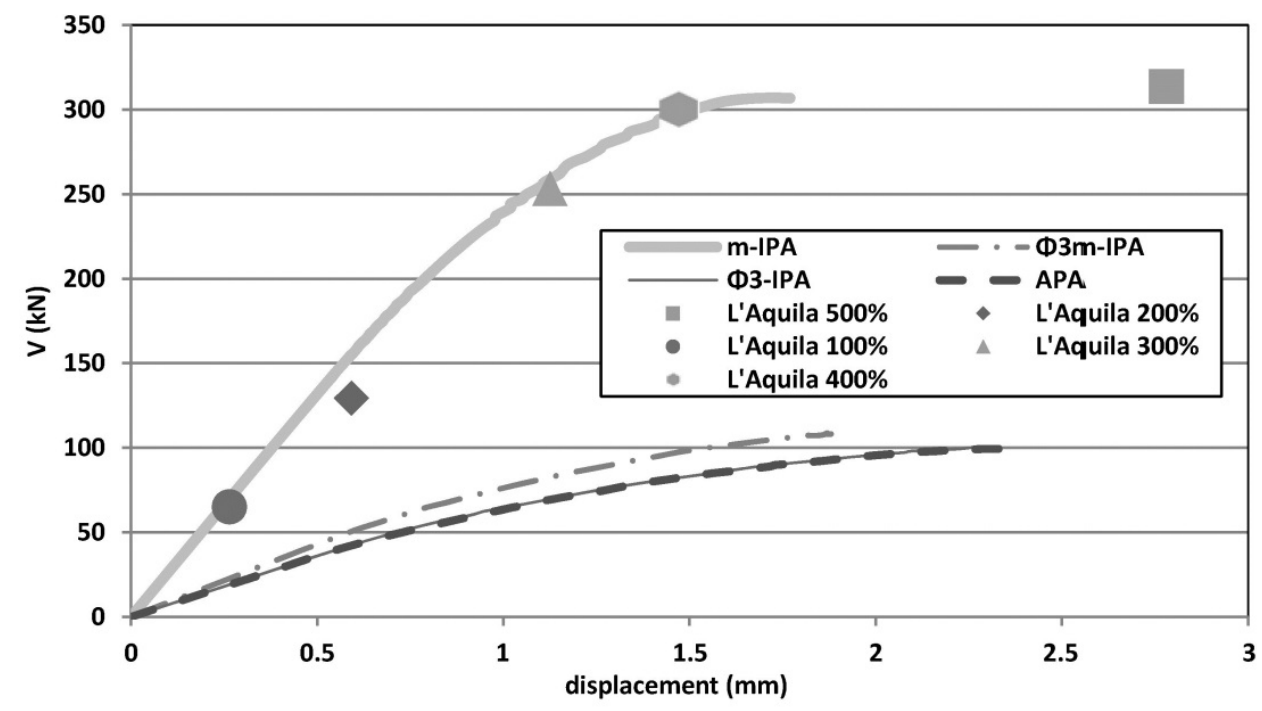

Figure 8 - Four-wall building: base-shear vs. displacement curves for different pushover analyses and NDA maxima obtained from L'Aquila earthquake accelerograms.

(a)

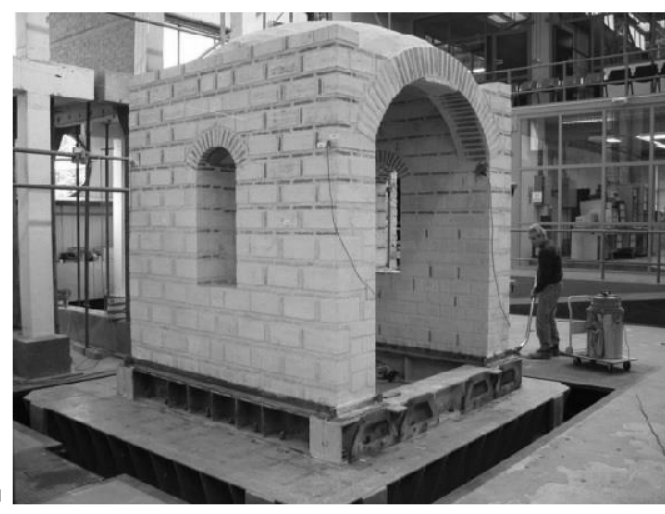

(b)

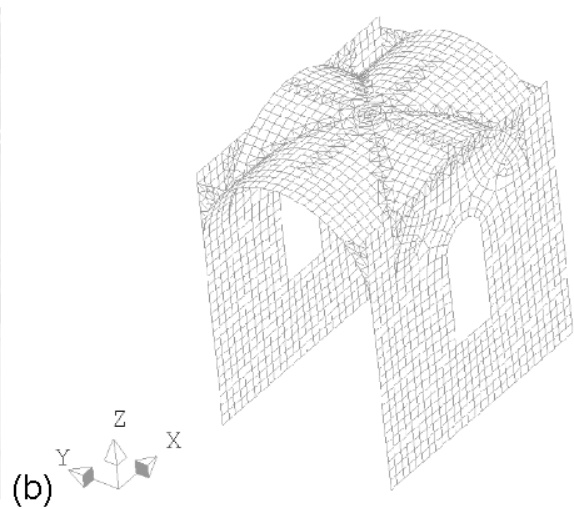

Figure 9 - Reduced-scale two-wall building with cross vault: (a) before testing in the laboratory and (b) FEM model. 


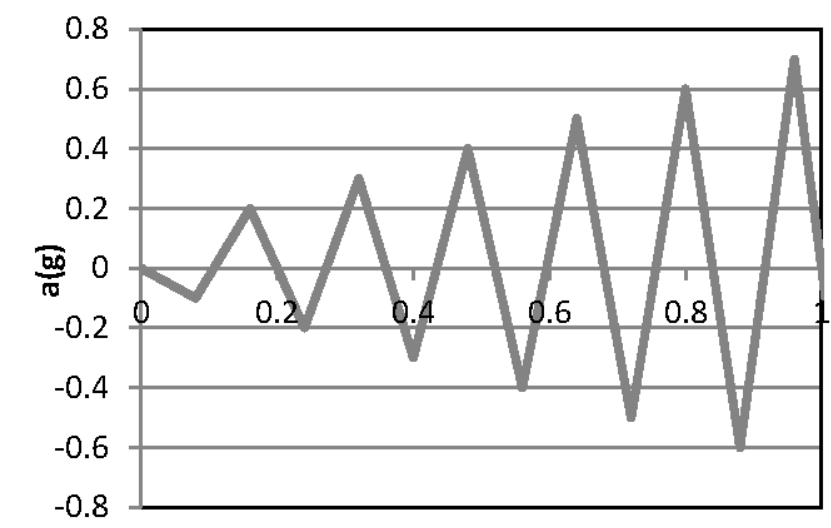

(a)

Time (s)

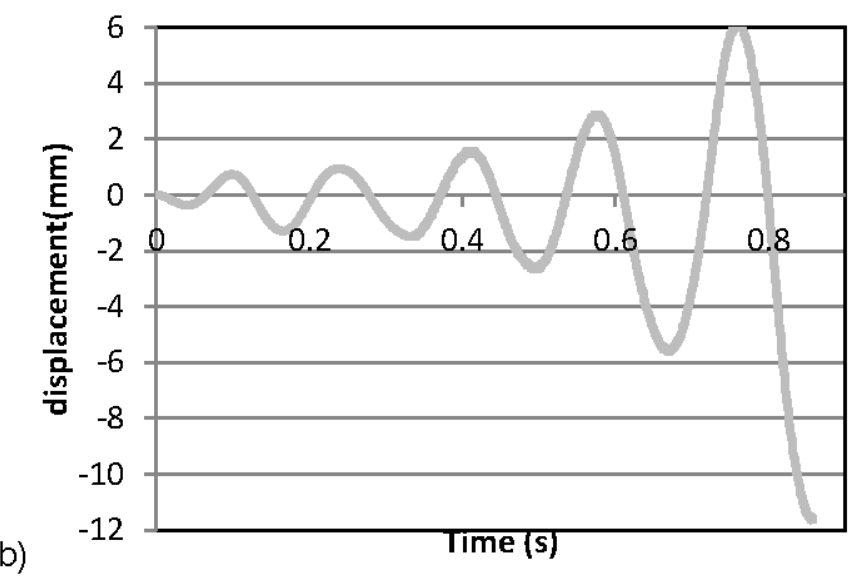

Figure 10 - NDA of the two-wall building with cross vault: (a) adopted simple artificial accelerogram and (b) time history of displacement at the top of the wall. 


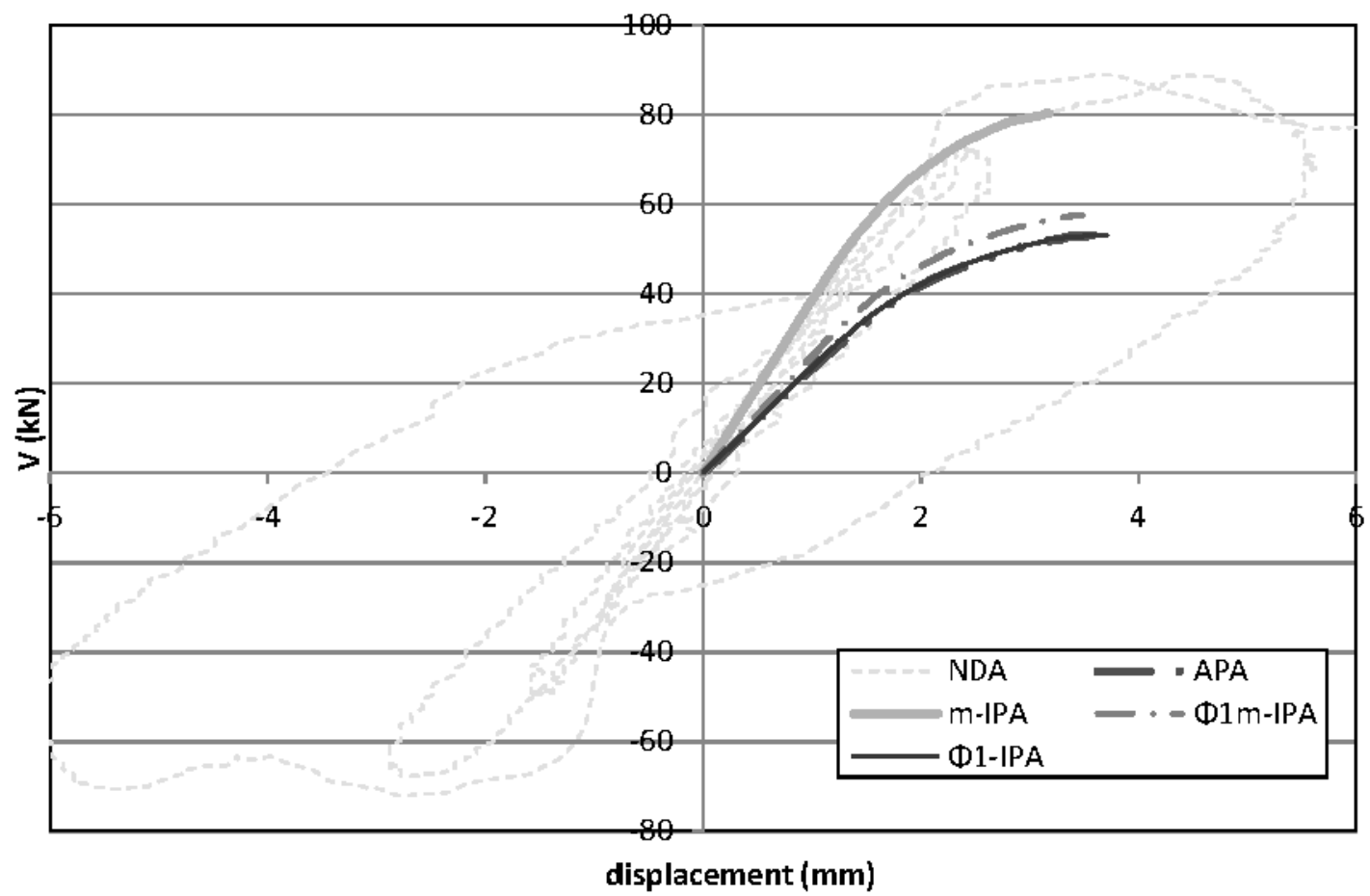

Figure 11 - Two-wall building with cross-vault: base-shear vs. displacement curves for different pushover analyses and NDA with artificial accelerogram.

(a)

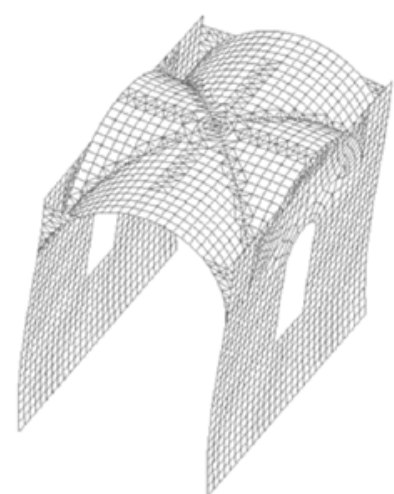

(b)

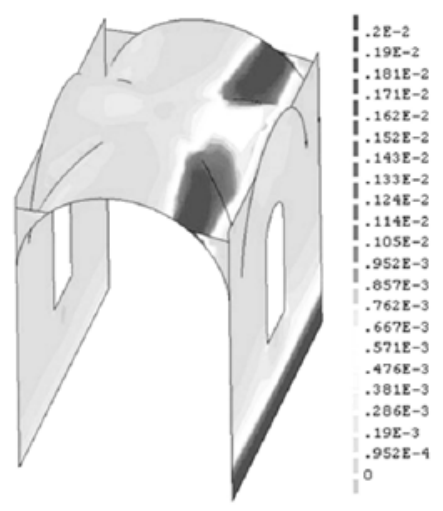

Figure 12 - Deformed shape of the $1^{\text {st }}$ mode in the $Y$ direction (a) and principal strain contours for NDA with artificial accelerogram at 0.828 seconds $(b)$. 


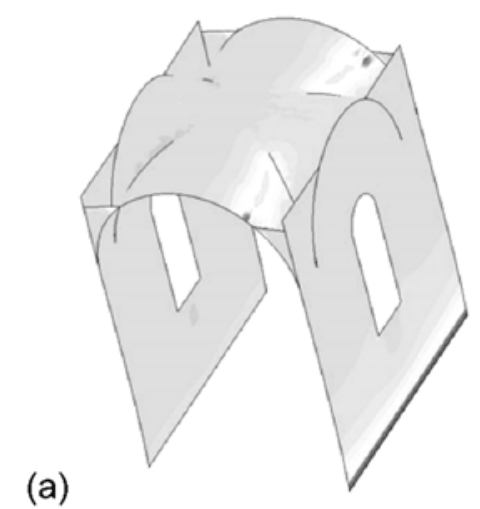

(b)

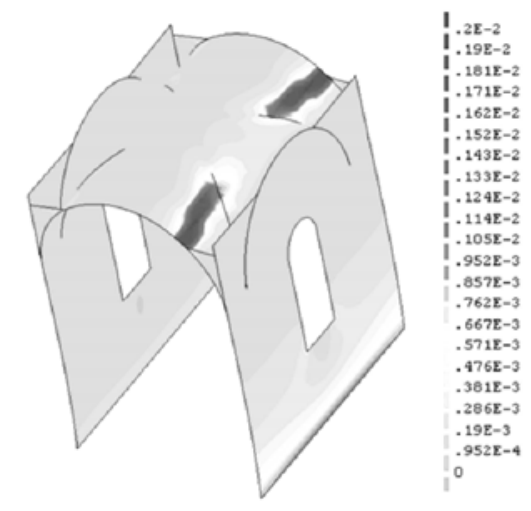

(c)
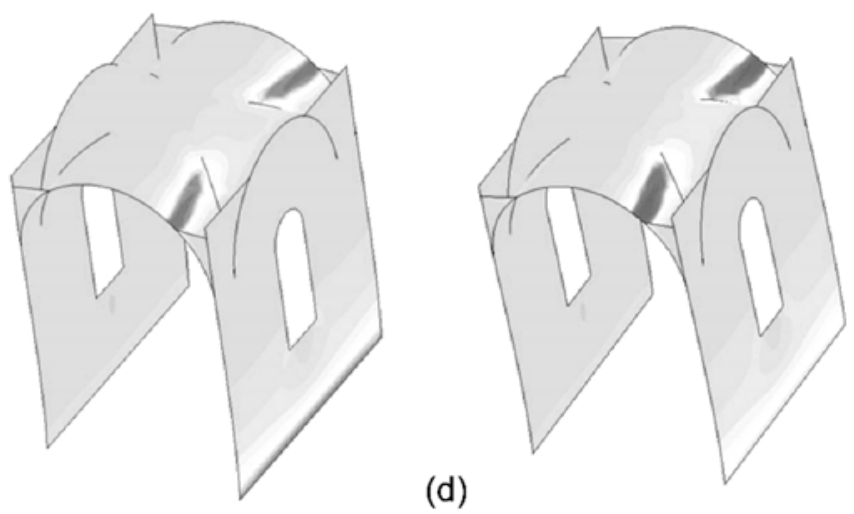

(d)

Figure 13 - Principal strain contours at the ultimate state for: (a) m-IPA, (b) $\Phi_{1}-$ IPA and (c) $\Phi_{1} m$ IPA and (d) APA. 


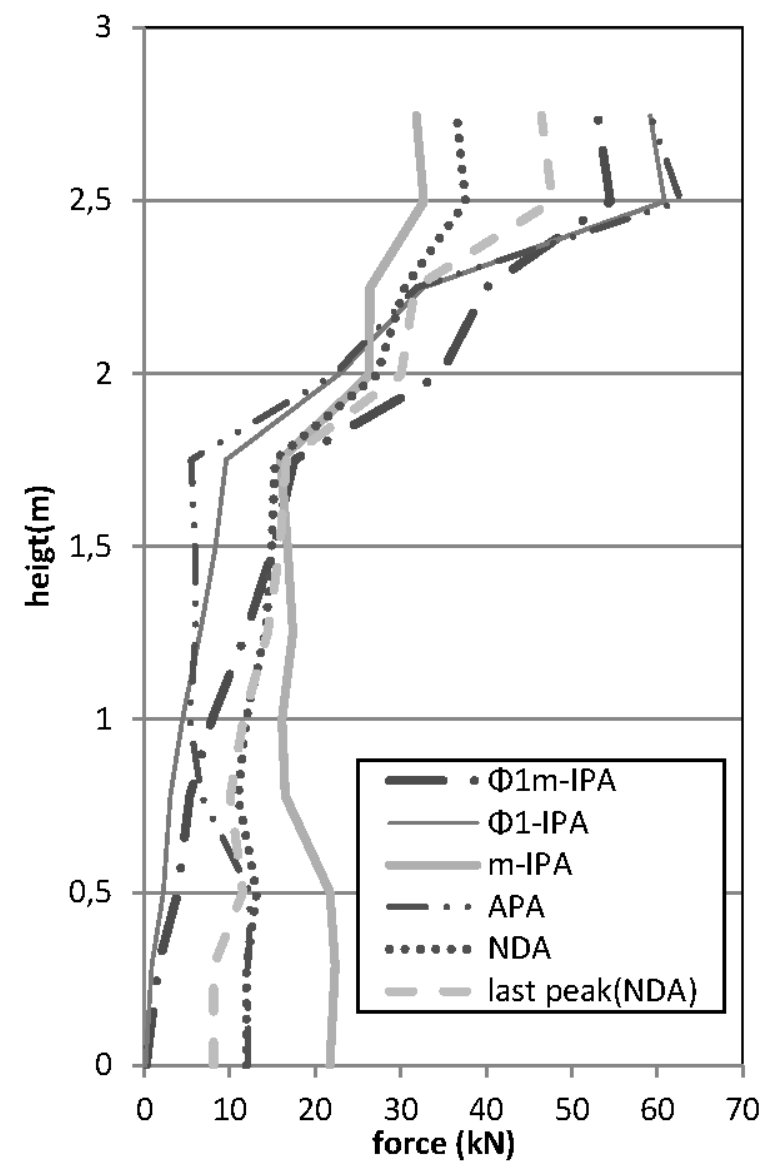

Figure 14 - Two-wall building with vault: comparison of lateral force distribution patterns among pushover analyses and NDA with artificial accelerogram. 


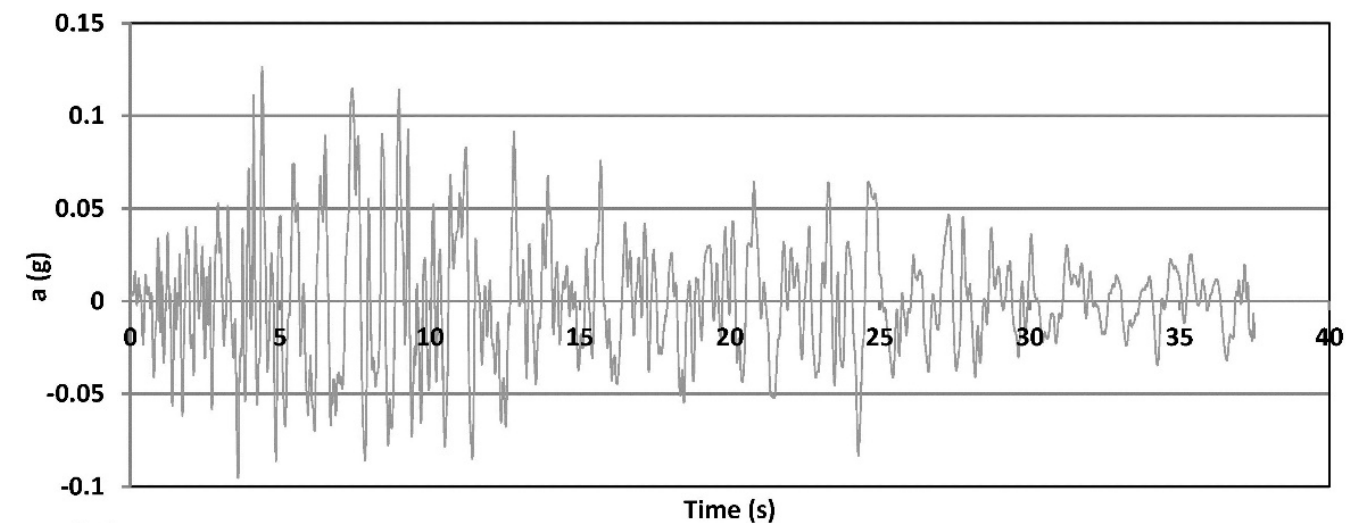

(a)

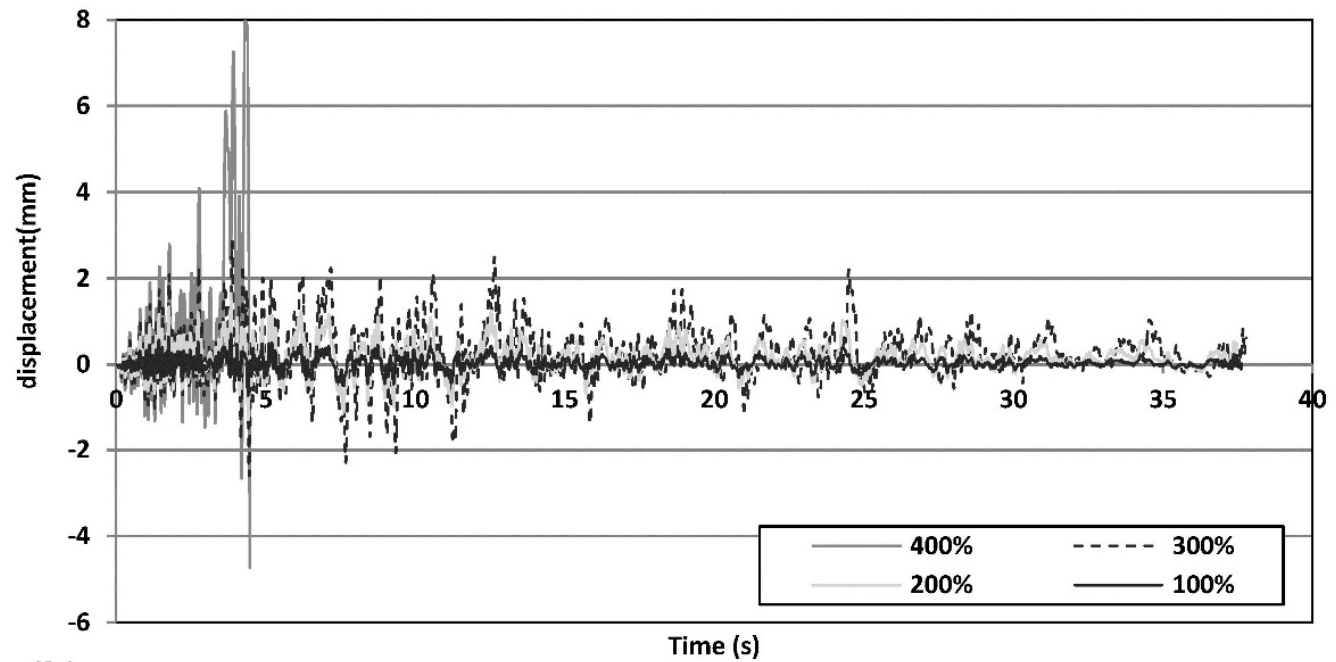

(b)

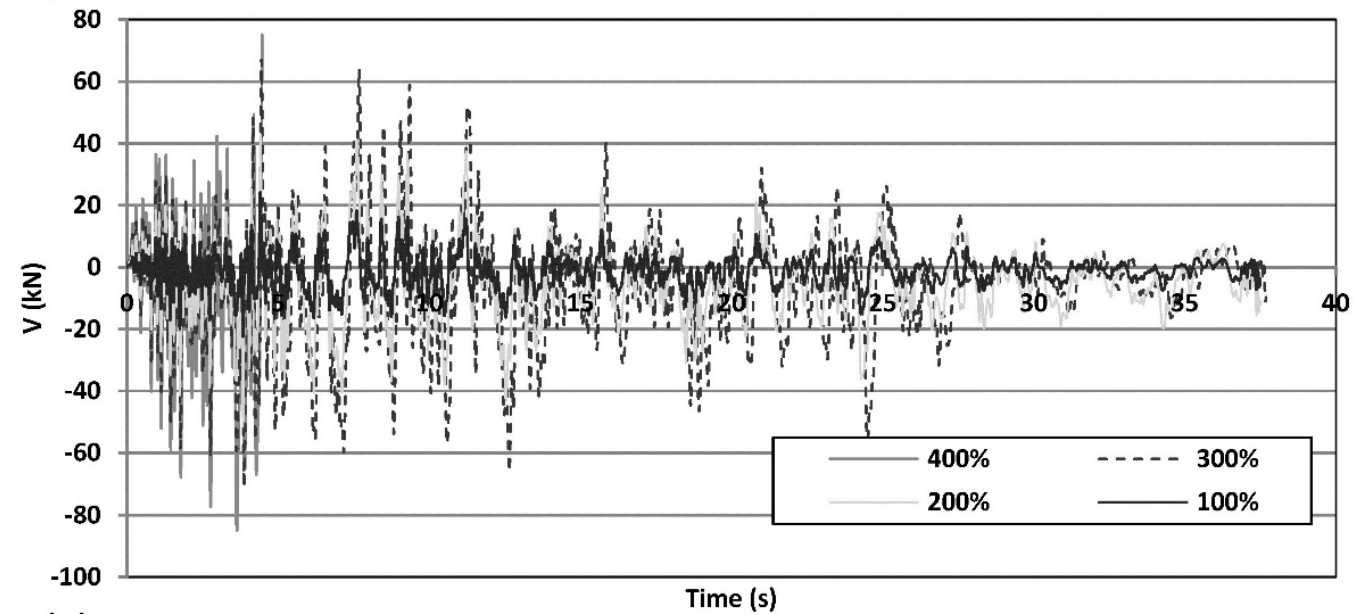

(c)

Figure 15 - NDA of the two-wall building with vault: natural accelerogram of 1980 Irpinia earthquake (a), time-histories of displacement (b) and base shear (c) for different magnitudes $(100 \%-400 \%)$. 


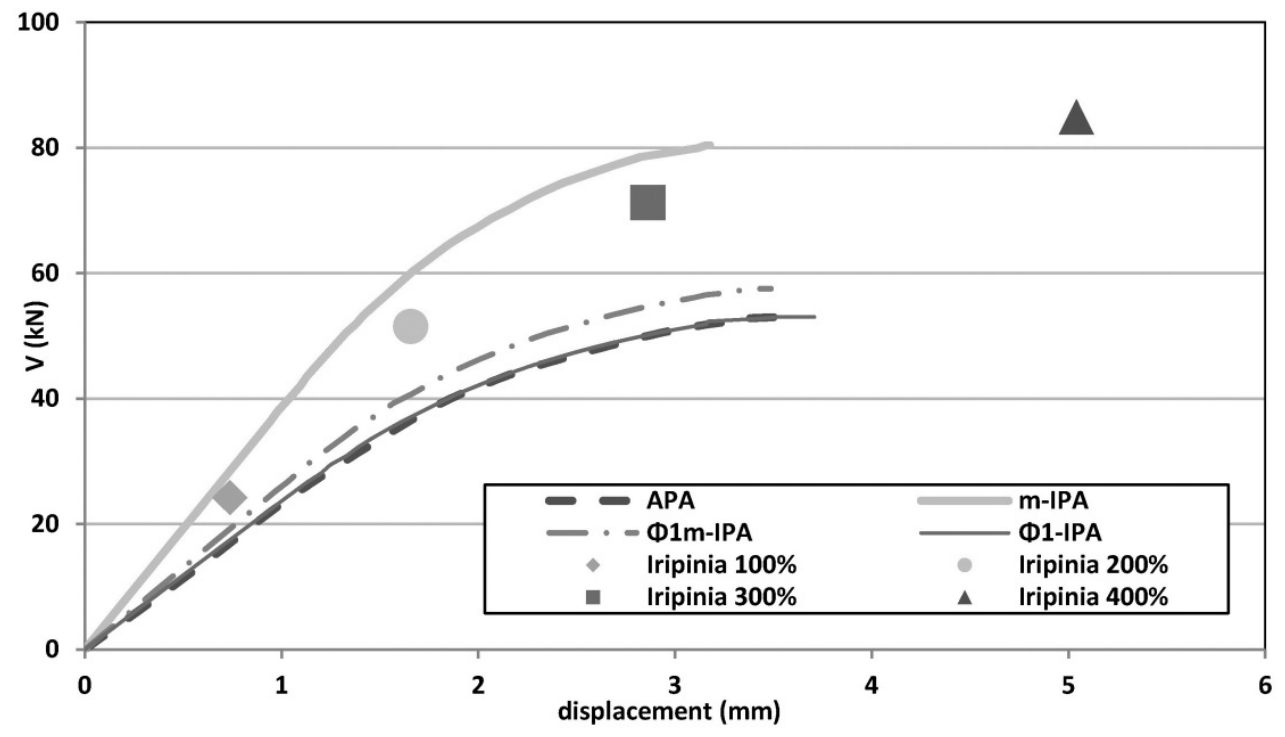

Figure 16 - Two-wall building with vault: base-shear vs. displacement curves for different pushover analyses and NDA maxima obtained from Irpinia earthquake accelerograms. 